\title{
MAKING SOAP FROM WASTE COOKING OIL AS A CREATIVE PRODUCT AND BEHAVIORAL CHANGE IN HOUSING AREA
}

\author{
Ni Luh Made Vinaya MEDHIATIKA \\ Sahid University, Jakarta, Indonesia \\ made_vinaya@usahid.ac.id
}

\begin{abstract}
Large consumption of cooking oil may cause water pollution, especially in the housing area. These community developments aim to change the behavior of households to recreate waste cooking oil to become a multipurpose natural soap. A housewife or a working mom can be an entrepreneur for this creative product. Specifically, it is called an ecopreneur because of the green product. Soap can promote and sell through social media such as Instagram. Online workshops, observation, and interviews were used as a method to run this project. The result can be found that someone who cares about the environment will take a little step to make a big change. She also encourages her neighborhoods and also food stalls not just to throw away the cooking oil waste but make it more useful. She used this soap, not only for individual use, give it to those who want it, and also for souvenirs. Instagram with hashtags figure does works for promotion specially to create positive electronic word-of-mouth (e-WOM). Instagram also can make it possible to reach green consumers, not only for selling purposes but to build awareness, creativity, and relationship with other green consumers together to save the environment and make a sustainable living.
\end{abstract}

Keywords: Waste Cooking Oil, Natural Soap, Ecopreneur, Instagram, Green Consumer

\section{BACKGROUND}

There is still a huge consumption of cooking oil in Indonesia. Databoks released data stated that Indonesia is the number 1 country that consumes cooking oil. This data supported by Global Agricultural Information Network USDA in 2019 data show that there is 13.110 metric ton consumption of cooking oil. People, especially households still using it for cooking. One study from (Pu et al., 2019) calculated that the cooking oils used in these dishes were analyzed in terms of the cooking process, food material combination, types of primary food materials, type of cooking oil, and the purpose of the cooking oil. The results showed that the mean amount of cooking oil used per 100 $\mathrm{g}$ of food material was $8.1 \mathrm{~g}$. There were no significant differences in the amount of cooking oil used in the eight major styles of Chinese cuisine. The average amount of cooking oil used in hot dishes (10.0 g) was higher than that used in cold dishes. The amount of cooking oil in pure meat, mixed meat-vegetable, and pure vegetable dishes was up to $10.9 \mathrm{~g}, 9.3 \mathrm{~g}$, and $4.6 \mathrm{~g}$, respectively. Many Indonesian dishes are acculturated with Chinese cuisine, so there may be similarities in the consumption of cooking oil. Even there are many studies about the disadvantage of cooking oil, still, the consumption rate is high. According to research held by (Yu Zhang et al., 2021)food-based evidence supporting the consumption of cooking oils in relation to total and cardiometabolic mortality remains largely absent. We aim to prospectively evaluate the relations of cooking oils with death from cardiometabolic (CVD and diabetes, there is increasing evidence highlights healthy dietary patterns and links daily cooking oil intake with chronic diseases including cardiovascular disease (CVD) and diabetes. Results have shown that people should replace cooking oil with another kind of oil because substituting corn oil, canola oil, or olive oil for equal amounts of butter and margarine was related to lower all-cause mortality and mortality from certain causes, including CVD, diabetes, cancer, respiratory disease, and Alzheimer's disease.

Not only from the healthiness side but cooking oil waste can also be one source of water pollution in the housing area. An article from the Ministry of PUPR stated that household waste has a bad impact on the environment. Many people do not realize the magnitude of the influence of household waste on people's lives and environmental sustainability. Channeling household waste into the wild without going through the processing process, will bring long adverse impacts to the survival of the ecosystem. Scientifically, the remaining oil can be used for several things such as those in research conducted by (Astuti \& Mufrodi, 2019) which waste cooking oil is very potential to be utilized as the raw material of biodiesel. Currently, there are 3.75 million liters of waste cooking oil per year. Waste cooking oil when discharged into the body of water will form a layer so that oxygen is blocked into the water. The utilization of waste cooking oil into biodiesel will reduce the burden of environmental pollution by waste cooking oil. This paper proposes optimum conditions of biodiesel production from waste cooking oil using a continuously stirred tank reactor with a base catalyst.

On a household scale, cooking oil waste can be useful as an ingredient of soap. This statement is supported by researches from (Tsai, 2019) and (Evelyn et al., 2019). According to (Tsai, 2019) waste cooking oil (WCO) has been considered a low-cost and renewable feedstock for the production of biodiesel and bio-based products if it can be economically and efficiently collected and recycled. It shows that the collected amounts of WCO from residential and commercial sectors in Taiwan significantly increased from 1599 tonnes in 2015 to 12,591 tonnes, reflecting on the WCO recycling regulation effective since 2015. Practically, the most important option for this urban mining is to reuse WCO as an energy source for the productions of biodiesel and auxiliary fuel. Other non-fuel related uses 
include the production of soaps/detergents, C-18 fatty acids, and lubricants. Another point of view from (Evelyn et al., 2019) with opinion that cooking oil that has been used more than once is not good for health due to exposure to carcinogens. Waste cooking oil causes pollution to the environment. Waste cooking oil can be used as a raw material for making liquid soap. Evaluation results showed that $100 \%$ community understood on making homemade dishwashing-liquid soap and 90\% community agreed that liquid soap from waste cooking oil has a commercial potential, which could increase entrepreneurship ability and economic growth of Batu Bersurat villagers. This soap can be used to wash kitchen cloth and else. Soap can be used individually or make a creative product for souvenirs.

A housewife can make a behavior change to save the environment. This term is supported by research from (Hale, 2018)this paper suggests that contrast with the default and transition into conscious adoption of the default design may be the starting point to establish long-term changes in consumer behavior. Despite the rooting of default rules in subconscious decision-making, this research finds that, ultimately, awareness drives the demand necessary for the creation of sustainable consumption. Whereas direct appeal to individuals has a disappointing level of influence on sustainability choices, it is understood that green consumers do come from somewhere. Green default rules offer interesting prospects for sidestepping the drawbacks of direct marketing to individuals. Under green default rules, behavior is guided by a default, such as utilities automatically sending customers renewables-sourced instead of fossil-fuel-based energy. To act otherwise requires additional effort and is less likely. Motivated by a need to understand how defaults might bridge standards and sustainable consumption, I investigate how organizational processes potentially lead from standardized green default rules to individual awareness that can spread and facilitate sustainable consumption. This paper examines the Active House sustainable building demonstrations in Europe in order to understand how (1 which this research finds that, ultimately, awareness drives the demand necessary for the creation of sustainable consumption. Green default rules offer interesting prospects for sidestepping the drawbacks of direct marketing to individuals. This paper also examines the Active House sustainable building demonstrations in Europe to understand how (1) communications and market creation and (2) responsible, user-centered experimentation are organized to move from defaults to sustainable consumption. Other research from (Yongsheng Zhang \& Chabay, 2020)knowledge of ecologically and socially sound products and practices investigates how "green knowledge" (i.e., knowledge of ecologically and socially sound products and practices) influences sustainability in the intersections of knowledge, preferences, behavior, and economic and environmental performance. Consumers, producers, and industry regulators with different degrees of knowledge and concern about the health and environmental benefits of products and production would lead to different economic and environmental consequences. As "green knowledge" influences consumption patterns and government policymaking, in principle, there will be a shift in the content of the economy to that which supports the achievement of long-term sustainability.

A change of behavior and motivation to use their "green knowledge" a housewife or a working mom can also be an entrepreneur that produces and sell a product that related to the green product such as natural soap from cooking oil waste. This type of change is called an ecopreneurship. Based on the research result from (Rodríguez-García et al., 2019) that identify an ecopreneurial businesses. These businesses are pioneers in using innovation to achieve sustainable growth by exploiting market opportunities. This article presents an overview of the concepts of ecopreneurship, ecoinnovation, and the ecological sector. The results of this review show the key values and principles that are central to this new stream of research and shed light on opportunities for further research. The primary conclusion is that there is a need for collaboration between ecopreneurs, consumers, and producers to achieve long-term sustainability. One article from (Kardos et al., 2019) aims to provide an integrative vision on green marketing roles in informing, raising awareness, educating, and changing consumer behavior towards sustainability and ecopreneurship. Green marketing can be whispered through the power of digital marketing, such as social media like Instagram. Instagram has many features to conduct marketing communication, using hashtags and tell stories, spread positive word of mouth, and selling implicitly at the small scale of friends, relatives, or communities. (Jain et al., 2020) released that globalization and economic growth have brought substantial shifts in consumption practices, production, and technology revolution in the wake of a sudden spurt of social media usage among young consumers. Social media platforms have become a reliable source of communication with consumers and are shaping consumers' purchase intentions. Therefore, a framework was developed to explain and empirically verify the factors shaping green purchase intentions. Three factors Social media usage, Interpersonal Influence, and E-WOM have been taken as exogenous variables. The impact of social media usage was found to be most influential on purchase intention. The findings of the study will aid marketers to better understand how social media plays an important role in shaping consumers' purchase intentions and how social media can be leveraged in a better way to encourage green consumption among millennials.

Another study from (Pop et al., 2020) revealed that social media contributed to a green consumption trend that shaping consumers' attitudes into more environmentally conscious behavior. The present study applied the Theory of Planned Behavior (TPB) to explain the impact of Social 
Media on consumers' purchase intention and motivation (altruism and egoism). The results indicate the importance of social media on consumers' attitudes, subjective norms, altruistic and egoistic motivations, and the impact of these variables as the antecedents of green cosmetics purchase intention. They also revealed that external factors such as social media as an information source, have an important role in consumer motivation formation and green cosmetic purchasing intentions. These findings are relevant for marketers to implement better communication strategies on social media to increase consumers' motivations and purchase intention toward green cosmetics.

Based on all backgrounds and research findings that why there is a need for a community development program to support those who are willing to make a small change for a big impact on the environment.

\section{METHODS}

As in the proposal, this program should be conducted in a housing area in Cinere, Depok area. Unfortunately, the implementation of community service overlaps with the implementation of restrictions on activities or PPKM. This time cannot hold meetings let alone in groups. Well, there is always a way to do a good thing, where there is Sustainable Indonesia, a group activist engaged in environmental sustainability. Sustainable Indonesia held a soap-making workshop both from the waste from cooking oil and other natural soaps. The first method with observation where the promoters and partners participated in this workshop is run through the WhatsApp group platform, 1 zoom meeting, and also through YouTube channel. From all residents that participated in this workshop, then selected one who excelled or was called a Champion. The chosen one, Maria Valentina, one of the residents who after attending the workshop directly accomplished to make soap from the waste of cooking oil. She agreed to be guided because she wants to be an agent of change for the environment, and she wanted to make soap for her use or sold on a small scale for her neighbors and church community. The next method is to interview via WhatsApp and phone, and also observation during soap making, and documentation is done for the running of the program. Documents are provided in the photo and also available on the YouTube channel.

\section{RESULT AND DISCUSSIONS}

The workshop conducted by Sustainable Indonesia provides an overview that household waste such as waste cooking oil can be processed into useful soaps. Participants who excelled as champions demonstrated changes in behavior towards the environment. One of the participants that were chosen as a champion, Maria Valentina, a working mother, collects waste cooking oil not only from the house around her, but also from food vendors such as fried foods, martabak, and all food stalls that use oil for frying. Soap is made according to her own needs or made by order. Sometimes, she gives the soap for free. But if the soap is made for sale, it is still on a limited scale, only to close friends, family, and the church community. Here, example of her soap that made from waste cooking oil:

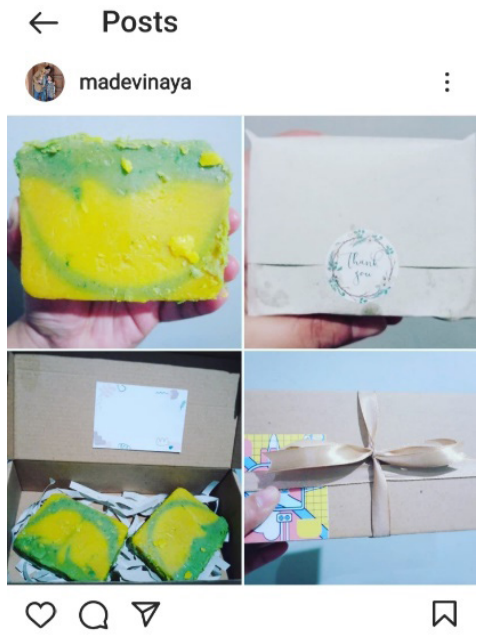

Picture 1. Soap and packaging

Source: Instagram account @madevinaya

Picture 1 above shows that cooking oil waste can be processed into a useful soap. The manufacturing process requires other materials such as carbon for residual oil purifiers, dyes, and also deodorizers. The maker can choose a color and make the soap look more attractive (if without the color will be only brown). Soap is produced to standard size but it is possible to produce as requested by the customer (customize). Packaging for soap is also selected which is environmentally friendly. The first option, the soap will be packed with baking paper and given stickers to redecorate. The second option, which can be for souvenirs, with reusable cardboard boxes. As the final touch of the packaging, it will be given a ribbon. From that figure also can declare that Indonesia needs more organizations like Sustainable Indonesia and people like Maria Valentina to do a small change for a big impact on the environment. The change of behavior that concerns sustainable living as stated in (Hale, 2018) this paper suggests that contrast with the default and transition into conscious adoption of the default design may be the starting point to establish long-term changes in consumer behavior. Despite the rooting of default rules in subconscious decision-making, this research finds that, ultimately, awareness drives the demand necessary for the creation of sustainable consumption. Whereas direct appeal to individuals has a disappointing level of influence on sustainability choices, it is understood that green consumers do come from somewhere. Green default rules offer interesting prospects for sidestepping the drawbacks of direct marketing to individuals. Under green default rules, behavior is guided by a default, such as utilities automatically sending customers renewables-sourced instead of fossil-fuel-based energy. To act otherwise requires additional effort and is less likely. Motivated 
by a need to understand how defaults might bridge standards and sustainable consumption, I investigate how organizational processes potentially lead from standardized green default rules to individual awareness that can spread and facilitate sustainable consumption. This paper examines the Active House sustainable building demonstrations in Europe in order to understand how ( 1 is that modern environmentalism is now changing the amount of attention paid to the environmental impact of residential housing. The prospect is attractive; a rule must be applied to support the change. One example of the rule that can be applied is Green default rules - rules that determine sustainability-oriented default behavior are increasingly used as a policy tool and are being designed into homes. Green default rules are promoted as valuable because of their higher effectiveness compared to that of awareness campaigns. The standardization of default green rules paints an intriguing picture of a sustainable future wherein the home is no longer a black box, but an innovation hub for experimenting with green default rules that alter what we take for granted, ideally for the good of society. green default rules need to simultaneously target different parts of society to have a larger-scale impact.

After attending the workshop, Maria Valentina had a strong desire to become an entrepreneur. Characteristics have a passion and creativity seen from the mother of two children. If seen from the entrepreneurial side, she can enter into an ecopreneur and if seen from the product side, then this soap product is included in the green product. This state is lined with a study from (Bhansing et al., 2018) that the results also suggest two factors of localized passion: passion atmosphere and passion in others. In other words, the more the location as a whole is characterized by passion (localized passion), the more the individual entrepreneurs are inspired to turn their creative ideas into creative products or services. The term of ecopreneurs as written in (Rodríguez-García et al., 2019) is a portmanteau word formed from combining the form eco (as in ecological) and entrepreneurship. Thus, ecopreneurship is the search for new opportunities that help protect the environment in pursuit of environmental sustainability. This study also contributes to the literature by exploring the links between ecopreneurship and ecoinnovation. Both of these terms are based on the pursuit of environmental-friendliness. In this framework, it is crucial to note the key role of consumers in promoting green practices and choosing organic products. A green product is described as something which produces low pollution, saves on resources, and is recyclable (Speer, 2011) on (Al-Gasawneh \& Al-Adamat, 2020). These products are known as ecological or environmentally friendly, and it is often found that these products involve recycling to some degree, less packaging than traditional products, or fewer toxic materials employed in production or packaging. Green purchase intention is a necessary aspect of the actual green buying behavior of a consumer, and denotes that a customer aims to purchase a green product if it is attractive to them.

Green products need green marketing, one that can be reached by social media as one of the marketing communication tools. To show how to make natural soaps, promote, and implicitly do sales, Maria Valentina uses YouTube and Instagram to do these tasks. These is an example of feed that inform the natural soap in Instagram:

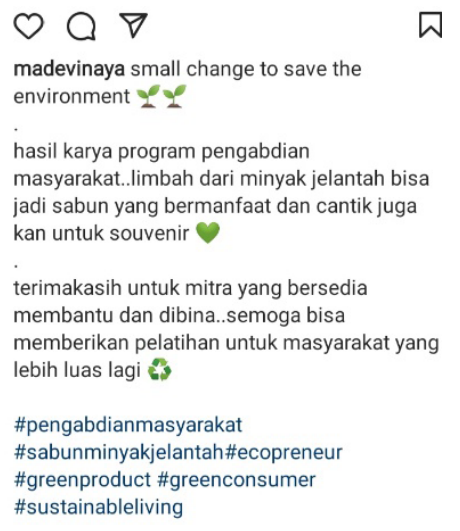

Picture 2. Instagram feed and use of hashtags

Source: Instagram account @madevinaya

Picture 2 shows the display of posts on feeds with content about product success and the slightest behavioral changes can have a good impact on the environment. Feeds come with hashtags (\#) to match product descriptions and target consumers to make them easier to find and will appear if there are similar posts. Followers who read will respond by clicking the like (heart) button, commenting, sharing information with other followers, or saving this information. Interested followers can contact via the direct message feature. For followers who have already used this product can also provide a review that can be written on the comment column. The more positive reviews, the more positive e-WOM will be and many will follow the love behavior of this environment. Social media platforms, as shown in (Umair Manzoor et al., 2020) that successful marketing and promotion strategies achieve customer development, profitability, and long-term company success. The results show that trust and social media influence significantly affect consumers' purchase intentions. Data analysis reveals that social media marketing has a greater influence than trust in purchase intentions through social networking sites. Instagram features such as hashtags (\#) and stories can be effective tools to reach consumers, especially green consumers. As explained in (Omena et al., 2020)the study of hashtag engagement requires a grasping of the functioning of the platform itself (technicity that hashtags as sociotechnical formations that serve social media research not only as criteria in corpus selection but also displaying the complexity of online engagement and its entanglement with the technicity of web platforms. Results show that there are three-layered (3L) perspectives for addressing hashtag engagement. The first contemplates potential 
differences between high-visibility and ordinary hashtag usage culture, its related actors, and content. The second focuses on hash tagging activity and the repurposing of how hashtags can be differently embedded into social media databases. The last layer looks particularly into the images and texts to which hashtags are brought to the relation. To enable identification and search, then on Instagram feed posts, soap maker can use hashtags (\#) such as; \#naturalsoap, \#soapfromwastecookingoil, \#greenproduct, \#greenconsumer, and \#sustainableliving.

As previously stated, small changes can have a huge impact on the environment. The demographic bonus that a country has, including millennials, can be an agent of change. Social media is also useful for electronic word of mouth or e-WOM. E-WOM costs of informal communication across the Internet aimed at consumers and linked with the usability or key properties of a product or service, or the brand behind them. The benefit of this tool is the fact that every single consumer can be involved, as anyone can share an experience online and post a review of a product for other users to read (Huete-Alcocer, 2017) (Al-Gasawneh \& Al-Adamat, 2020). Based on research by (Jain et al., 2020) globalization and economic growth have brought substantial shifts in consumption practices, production, and technology revolution in the wake of a sudden shot of social media usage among young consumers. Social media platforms have become a reliable source of communication with consumers and are shaping consumers' purchase intentions. Three factors Social media usage, Interpersonal Influence, and E-WOM have been taken as exogenous variables. The findings of the study will aid marketers to better understand how social media plays an important role in shaping consumers' purchase intentions and how social media can be leveraged in a better way to encourage green consumption among millennials. Other research from (Al-Gasawneh \& Al-Adamat, 2020) results of the analysis denoted that the E-WOM controlled the relationship of content marketing with green purchasing intentions. This denotes that clear and effective content marketing, involving suitably alluring content, can strongly encourage satisfied customers to share their positive experiences through EWOM, which in turn increases the interest of other customers towards green products. Instagram content should be provided with feeds that contains information about the advantages of the soap. This feeds can persuade consumer to buy and share their experience with positive words of the product. A combination of hashtags and positive e-WOM can persuade other housewives/ households to use soap made from waste cooking oil. They don't have to make it, simply buy the soap, use it, and review it with positive words to encourage others. E-WOM also can make new opportunity for ecopreneurship to produce more soap, not only for individual use but another use such as souvenirs. Natural soap with natural packaging can added value to the product and also can make a change for the environment.

\section{CONCLUSION}

Behavior changes to save the environment can start from the smallest environment that is the house. A housewife, equipped with training, can use waste cooking oil into soap that can be used alone, distributed for free for residential environments, and can also be sold even on a limited scale. The change is not only from behavior but the growing role of an entrepreneur. Entrepreneurs, especially women, can have an impact on their people. Specific to this program can include ecopreneur because the product produced is green. This product is targeted at green consumers because this segment is willing to buy. After all, it understands the impact on environmental sustainability. This consumer segment is also among those active in using social media. Through social media, especially Instagram can be a platform to provide information, knowledge, and become agents of change. Ready-made and uniquely packaged soap products are uploaded to the feed to attract followers. Good content will attract followers to give positive likes and comments, this is called positive e-word-of-mouth (e-WOM). Content should also include hashtags (\#) that can make searching easier and can appear on timelines connected to the same hashtags. An entrepreneur also has a creative mindset so it will not stop at soap products from waste cooking oil alone. Other products in the form of natural soap from other materials such as olive oil with natural fragrances that can be used for bathing and it is also safe for the environment. Currently still conducting experiments or trial and error to produce shampoos without the use of palm oil. The limitations of this program at the time, while a housewife and also working mother, the time for production is very limited. Another limit is the absence of licenses from BPOM and trademarks that can provide more value for an entrepreneur.

\section{ACKNOWLEDGMENT}

Thank you to LPPM Sahid University Jakarta for this opportunity and material support for this community development program. Also, thanks to Sustainable Indonesia provide a workshop to make natural soap.

\section{REFERENCE}

Al-Gasawneh, J. A., \& Al-Adamat, A. M. (2020). The mediating role of e-word of mouth on the relationship between content marketing and green purchase intention. Management Science Letters, 10(8), 1701-1708. https://doi.org/10.5267/j. msl.2020.1.010

Astuti, E., \& Mufrodi, Z. (2019). Optimum condition of biodiesel production from waste cooking oil using continuous stirred tank reactor. International Journal of Smart Grid and Clean Energy, 8(2), 201-205. https://doi.org/10.12720/sgce.8.2.201-205

Bhansing, P. V., Hitters, E., \& Wijngaarden, Y. (2018). 
Passion Inspires: Motivations of Creative Entrepreneurs in Creative Business Centres in the Netherlands. Journal of Entrepreneurship, 27(1), 1-24. https://doi.org/10.1177/0971355717738589

Evelyn, E., Saputra, E., Komalasari, K., \& Utami, S. P. (2019). Community training in dishwashingliquid soap making from waste cooking oil. Riau Journal of Empowerment, 1(2), 67-74. https://doi. org/10.31258/raje.1.2.9

Hale, L. A. (2018). At home with sustainability: From green default rules to sustainable consumption. Sustainability (Switzerland), 10(1). https://doi. org/10.3390/su10010249

Jain, V. K., Gupta, A., Tyagi, V., \& Verma, H. (2020). Social media and green consumption behavior of millennials. Journal of Content, Community and Communication, 10(6), 221-230. https://doi. org/10.31620/JCCC.06.20/16

Kardos, M., Gabor, M. R., \& Cristache, N. (2019). Green marketing's roles in sustainability and ecopreneurship. Case study: Green packaging's impact on Romanian young consumers' environmental responsibility. Sustainability (Switzerland), 11(3), 1-12. https://doi.org/10.3390/ su11030873

Omena, J. J., Rabello, E. T., \& Mintz, A. G. (2020). Digital Methods for Hashtag Engagement Research. Social Media + Society, 6(3), 205630512094069. https:// doi.org/10.1177/2056305120940697

Pop, R. A., Saplacan, Z., \& Alt, M. A. (2020). Social media goes green-the impact of social media on green cosmetics purchase motivation and intention. Information (Switzerland), 11(9). https://doi. org/10.3390/INFO11090447
Pu, G., Zheng, M., Lu, S., \& Huang, J. (2019). Study on the use of cooking oil in Chinese dishes. International Journal of Environmental Research and Public Health, 16(18), 1-7. https://doi.org/10.3390/ ijerph16183367

Rodríguez-García, M., Guijarro-García, M., \& CarrileroCastillo, A. (2019). An overview of ecopreneurship, eco-innovation, and the ecological sector. Sustainability (Switzerland), 11(10). https://doi. org/10.3390/su11102909

Tsai, W. T. (2019). Mandatory recycling of waste cooking oil from residential and commercial sectors in Taiwan. Resources, 8(1). https://doi.org/10.3390/ resources 8010038

Umair Manzoor, Sajjad Ahmad Baig, Muhammad Hashim, \& Abdul Sami. (2020). Impact of Social Media Marketing on Consumer's Purchase Intentions: The Mediating role of Customer Trust. International Journal of Entrepreneurial Research, 3(2), 41-48. https://doi.org/10.31580/ijer.v3i2.1386

Zhang, Yongsheng, \& Chabay, I. (2020). How "green knowledge" influences sustainability through behavior change: Theory and policy implications. Sustainability (Switzerland), 12(16). https://doi. org/10.3390/su12166448

Zhang, Yu, Zhuang, P., Wu, F., He, W., Mao, L., Jia, W., Zhang, Y., Chen, X., \& Jiao, J. (2021). Cooking oil/ fat consumption and deaths from cardiometabolic diseases and other causes: prospective analysis of 521,120 individuals. BMC Medicine, 19(1), 1-14. https://doi.org/10.1186/s12916-021-01961-2

https://databoks.katadata.co.id/datapublish/2020/08/12/ konsumsi-minyak-goreng-berdasarkan-jenis

http://plpbm.pu.go.id/v2/posts/Limbah-Rumah-Tanggadalam-Lingkungan-Permukiman 